\title{
Molecular Structure, Vibrational Assignments and Non-Linear Optical Properties of 4,4' Dimethylaminocyanobiphenyl (DMACB)
by DFT and ab Initio HF Calculations
}

\author{
Charef Tabti, Nadia Benhalima \\ Faculty of Sciences and the Technology, Laboratory of Technology and Properties of Solid (LTPS), University of \\ Mostaganem (UMAB), Mostaganem, Algeria \\ Email: tabti_ttps@yahoo.fr \\ Received 10 May 2015; accepted 19 July 2015; published 22 July 2015 \\ Copyright (C) 2015 by authors and Scientific Research Publishing Inc. \\ This work is licensed under the Creative Commons Attribution International License (CC BY). \\ http://creativecommons.org/licenses/by/4.0/ \\ (c) (i) Open Access
}

\begin{abstract}
In the present study, structural properties of 4,4' dimethylaminocyanobiphenyl (DMACB) have been studied extensively by using ab initio Hartree Fock (HF) and density functional theory (DFT) employing B3LYP/B3PW91 exchange correlation levels of theory. The vibrational frequencies of DMACB in the ground state have been calculated by using Hartree Fock level and density functional method (B3LYP/B3PW91) with 6-31G(d, p), basis set. Nonlinear optical (NLO) behavior of the examined molecule is investigated by the determination of the electric dipole moment $\mu$, the polarizability $\alpha$, and the hyperpolarizability $\beta$ by using the B3LYP/B3PW91 methods.
\end{abstract}

\section{Keywords}

Ab Initio, 4,4' Dimethylaminocyanobiphenyl (DMACB), Dipole Moment, Polarizability, Hyperpolarizability, Non-Linear Optics (NLO), Vibrational Spectra, Density Functional Calculations

\section{Introduction}

Non linear optical (NLO) phenomena are of significance because they form the basis of the optical processing and data storage. Therefore, they are important in the development of the future generations of communication systems and computers, and much effort has been devoted to increasing the useful non linearity of optical mate- 
rials [1] [2]. Depending on the particular application, the use of organic materials may offer majored vantages over conventional inorganic crystals [3] [4]. In the past years, considerable efforts focused on the development of organic materials with large molecular hyperpolarizabilities, improved optical transparency, etc. [5] [6]. For a material having useful and highly efficient nonlinear optical properties, the constituting molecules need first to exhibit large molecular hyperpolarizabilities, which are generally characterized by a highly extended $\pi$-conjugated chain with electron donor-acceptor pair at the ends (D- $\pi-A)$. The existences of strong intermolecular charge transfer excitations in a noncentrosymmetric molecular environment are key to the non linear optical activity. The first criterion can be satisfied by considering a polarizable molecular system (e.g. $\pi$ conjugated pathway) having an uneven or asymmetric charge distribution. The simplest way to achieve this is to have a donor (D) - acceptor (A) system with a bridge (D- $\pi-A$ ) which can help the electronic communication between the donor and the acceptor. In this study, the geometrical parameters, fundamental frequencies of the title compound in the ground state have been calculated by using the HF and DFT (B3LYP, B3PW91) methods with 6-31G(d, p) basis set. The non-linear optical properties are also addressed theoretically. The electric dipole moment $\mu$, the isotropic polarizability $\alpha$ and the first hyperpolarizability $\beta$ of the title compound are calculated.

DMACB is a derivative of a "Push Pull" molecule crystallises in a non centrosymetric group Cc, with four molecules in the unit cell. This molecule consists of the set of two benzene rings which are fixed to oppose an electron donor (dimethylamino group), characterized by Hammett coefficient $(-1.70)$ and an electron acceptor (cyano group) (electron-withdrawing by a Hammett's coefficient equal to 0.66). The positive value of Hammett coefficient reflects an electro-attractor acceptor effect. This compound is a very suitable material for the non-linear optics. Our objective is to design a range of molecular systems, which show NLO activity. The approach is based on the concept of charge transfer (CT) between donor and acceptor through a biphenyl. The designing of systems with high CT is key to this part, as intra molecular CT between the donor and acceptor will lead to a very large value for $\beta$.

\section{Computation Methods}

The HF theory applies the self-consistent field level and is thus very appropriate for such calculations. On the other hand, DFT was applied using the B3LYP which is the keyword for the hybrid functional [7], which is a linear combination of the gradient functional proposed by Becke [8] and Lee, Yang and Parr [9], together with the Hartree Fock local exchange function [10]. DFT was also applied using the B3PW91 functional, which implies its use of a three-parameter scheme, as well as, the generalized gradient approximation exchange and correlation functional B [7] and PW91 [11]. PW91 uses a different expression for the local density approximation and contains no empirical parameters. Calculations were performed using the Gaussian 03 [12]. The HF and DFT methods with 6-31G(d, p) basis set calculations were made first to optimize the structures. The vibrational frequencies and non-linear optical properties were calculated by means of the HF and DFT methods at the corresponding optimized geometries. All the calculations converged to an optimized geometry which corresponds to a true energy minimum as revealed by the lack of imaginary values in the calculate vibration frequencies. Vibration frequencies are calculated using HF/6-31G(d, p), B3LYP/6-31G(d, p), B3PW91/6-31G(d, p) and then scaled by 0.89, 0.95, and 1 respectively. In this work, to improve the agreement with experiment, the B3LYP/ 6-31G(d, p) harmonic frequencies were scalled by a factor of 0.95 . The NLO response calculation was performed on the optimized geometry using the same level of theory. The first static hyperpolarizability $\beta$ is a third rank tensor that can be described by a $3 \times 3 \times 3$ matrix. The 27 components of the 3D matrix can be reduced to 10 components due to the Kleinman symmetry [13] $\left(\beta_{x y y}=\beta_{y x y}=\beta_{y y x}, \beta_{y y z}=\beta_{y z y}=\beta_{z y y} \ldots\right.$, likewise other permutations also take same value). It can be given in the lower tetrahedral format. The output from Gaussian 03 provides 10 components of this matrix as $\beta_{x x x}, \beta_{x x y}, \beta_{x y y}, \beta_{y y y}, \beta_{x x z}, \beta_{x y z}, \beta_{y y z}, \beta_{x z z}, \beta_{y z z}, \beta_{z z z}$, respectively. Many types of hyperpolarizabilities have been discussed in the literature [14]. When reporting a single value of $\beta$, one of the common formats is to simply treat the three independent values for $\beta$ as a quasi-Pythagorean problem and solve for the average $\beta$ by Equation (1):

$$
\beta_{\text {tot }}=\left(\beta_{x}^{2}+\beta_{y}^{2}+\beta_{z}^{2}\right)^{\frac{1}{2}}
$$

The complete equation for calculating the magnitude of the total first static hyperpolarizability from Gaussian 03 output is given as Equation (2): 


$$
\beta_{t o t}=\left[\left(\beta_{x x x}+\beta_{x y y}+\beta_{x z z}\right)^{2}+\left(\beta_{y y y}+\beta_{y z z}+\beta_{y x x}\right)^{2}+\left(\beta_{z z z}+\beta_{z x x}+\beta_{z y y}\right)^{2}\right]^{\frac{1}{2}}
$$

\section{Results and Discussion}

\subsection{Molecular Parameters}

The atomic numbering scheme and the theoretical geometric structure for the title compound crystal [15] are shown in Figure 1 and Figure 2. The crystal structure of the title compound is monoclinic with space group Cc. The crystal structure parameters of the title compound are $a=9.503(2) \AA, b=16.429(6) \AA, c=8.954(4) \AA, \beta=$ $122.04(3) \AA$, The volume of the unit cell is $V=1185.0(8) \AA^{3}$ [15]. The optimized parameters (bond lengths and angles of the title compound have been obtained at the HF and B3LYP methods with 6-31G (d, p) basis set.

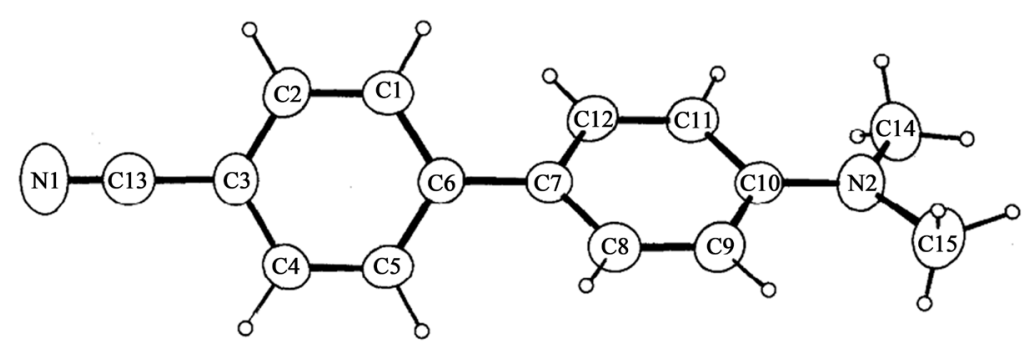

(a)

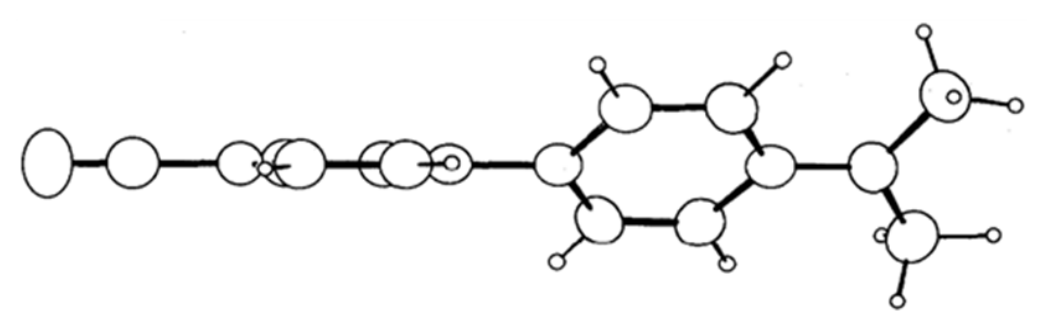

(b)

Figure 1. The DMACB molecule projected on a plane parallel. (a) and perpendicular; (b) to the cyanobenzene ring [15].
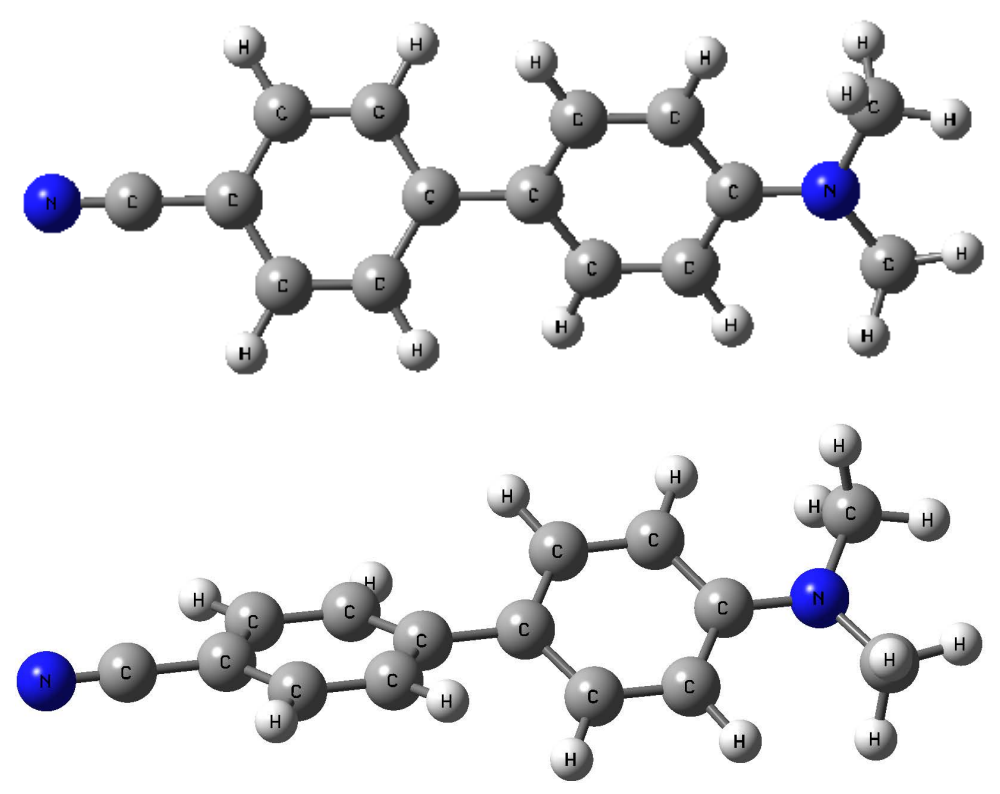

Figure 2. B3LYP/6-31G** optimized structure of 4, 4'dimethylaminocyanobiphenyl. 
These results are listed in Table 1 and Table 2 and compared with the experimental data of the title compound. The geometries predicted by the HF calculations are a little better than the DFT computations. For $\mathrm{C}(13) \equiv \mathrm{N}(1)$ distance, the good agreement between experiment and calculation was noticed. In real crystal, this distance is equal to $1.14 \AA$ and in DFT approach is a little bigger $(1.16 \AA)$. The all calculated C-H distances are very similar and equal $(1.085 \AA)$. In experimental results the differences are observed. These lengths are included in the range of $0.90-1.05 \AA$. from the theoretical values; it is noteworthy that most of the optimized angles have slightly larger values than the corresponding experimental ones, due to the fact that theoretical calculations imply isolated molecules in gaseous phase state while experimental results refer to molecules in the solid state.

\subsection{Assignments of the Vibration Modes}

The vibrational spectral studies also provide information about the charge transfer interaction between the donor

Table 1. Optimized geometry of DMACB calculated at the Hartree Fock, DFT levels of theory using the 6-31G(d, p) basis set (bond length ), with estimated standard deviations in parentheses.

\begin{tabular}{|c|c|c|c|c|c|}
\hline Atom 1 & Atom 2 & HF & B3LYP & B3PW91 & X-ray \\
\hline N1 & C13 & 1.137 & 1.164 & 1.164 & $1.144(3)$ \\
\hline N2 & C10 & 1.410 & 1.384 & 1.377 & 1.372(3) \\
\hline N2 & C14 & 1.453 & 1.453 & 1.446 & $1.435(3)$ \\
\hline N2 & C15 & 1.445 & 1.453 & 1.447 & $1.436(4)$ \\
\hline $\mathrm{C} 1$ & $\mathrm{C} 2$ & 1.381 & 1.388 & 1.386 & $1.377(3)$ \\
\hline $\mathrm{C} 1$ & C6 & 1.394 & 1.409 & 1.406 & $1.397(4)$ \\
\hline $\mathrm{C} 1$ & H1 & 1.075 & 1.085 & 1.086 & $1.010(4)$ \\
\hline $\mathrm{C} 2$ & $\mathrm{C} 3$ & 1.390 & 1.405 & 1.403 & $1.384(4)$ \\
\hline $\mathrm{C} 2$ & $\mathrm{H} 2$ & 1.075 & 1.085 & 1.085 & $1.000(4)$ \\
\hline $\mathrm{C} 3$ & $\mathrm{C} 4$ & 1.390 & 1.405 & 1.403 & $1.391(4)$ \\
\hline $\mathrm{C} 3$ & $\mathrm{C} 13$ & 1.444 & 1.432 & 1.430 & $1.438(3)$ \\
\hline $\mathrm{C} 4$ & $\mathrm{C} 5$ & 1.381 & 1.388 & 1.386 & $1.374(3)$ \\
\hline $\mathrm{C} 4$ & H5 & 1.075 & 1.085 & 1.085 & $1.010(3)$ \\
\hline $\mathrm{C} 5$ & C6 & 1.394 & 1.409 & 1.406 & $1.401(3)$ \\
\hline C5 & H5 & 1.075 & 1.085 & 1.086 & $1.000(4)$ \\
\hline C6 & C7 & 1.488 & 1.478 & 1.474 & $1.468(3)$ \\
\hline $\mathrm{C} 7$ & $\mathrm{C} 8$ & 1.395 & 1.405 & 1.403 & $1.393(4)$ \\
\hline C7 & C12 & 1.386 & 1.405 & 1.403 & $1.393(3)$ \\
\hline $\mathrm{C} 8$ & C9 & 1.377 & 1.388 & 1.386 & $1.382(3)$ \\
\hline C8 & H8 & 1.076 & 1.086 & 1.087 & $0.930(3)$ \\
\hline C9 & C10 & 1.398 & 1.415 & 1.413 & $1.397(3)$ \\
\hline C9 & H9 & 1.074 & 1.083 & 1.084 & $0.980(4)$ \\
\hline C10 & C11 & 1.391 & 1.415 & 1.413 & $1.394(4)$ \\
\hline C11 & $\mathrm{C} 12$ & 1.387 & 1.388 & 1.386 & $1.382(3)$ \\
\hline C11 & H11 & 1.073 & 1.083 & 1.084 & $1.050(3)$ \\
\hline $\mathrm{C} 12$ & H12 & 1.076 & 1.086 & 1.087 & $0.970(4)$ \\
\hline C14 & H14A & 1.080 & 1.096 & 1.097 & $0.920(4)$ \\
\hline C14 & H14B & 1.092 & 1.101 & 1.100 & $1.010(4)$ \\
\hline C14 & $\mathrm{H} 14 \mathrm{C}$ & 1.084 & 1.091 & 1.091 & $0.970(3)$ \\
\hline C15 & H15A & 1.093 & 1.091 & 1.091 & $1.050(4)$ \\
\hline C15 & H15B & 1.083 & 1.096 & 1.097 & $0.900(4)$ \\
\hline C15 & H15C & 1.084 & 1.100 & 1.100 & $1.050(3)$ \\
\hline
\end{tabular}


Table 2. Optimized geometry of DMACB calculated at the Hartree Fock, DFT levels of theory using the 6-31G(d, p) basis set (bond angle) with estimated standard deviations in parentheses.

\begin{tabular}{|c|c|c|c|c|c|c|}
\hline Atom 1 & Atom 2 & Atom 3 & HF & B3LYP & B3PW91 & X-ray \\
\hline C10 & N2 & C14 & 116.0 & 119.7 & 119.9 & $120.9(3)$ \\
\hline C10 & N2 & C15 & 117.3 & 119.6 & 119.8 & $121.2(2)$ \\
\hline C14 & N2 & C15 & 112.3 & 118.7 & 119.4 & $117.9(2)$ \\
\hline $\mathrm{C} 2$ & $\mathrm{C} 1$ & C6 & 121.0 & 121.5 & 121.4 & $121.4(2)$ \\
\hline $\mathrm{C} 1$ & $\mathrm{C} 2$ & $\mathrm{C} 3$ & 119.9 & 120.1 & 120.0 & $119.9(2)$ \\
\hline $\mathrm{C} 2$ & C3 & $\mathrm{C} 4$ & 119.8 & 119.2 & 119.3 & $119.9(2)$ \\
\hline $\mathrm{C} 2$ & C3 & C13 & 120.1 & 120.4 & 120.3 & $120.2(3)$ \\
\hline $\mathrm{C} 4$ & C3 & $\mathrm{C} 13$ & 120.1 & 120.4 & 120.3 & $119.8(2)$ \\
\hline C3 & $\mathrm{C} 4$ & C5 & 119.9 & 120.1 & 120.0 & $119.8(2)$ \\
\hline $\mathrm{C} 4$ & C5 & C6 & 121.0 & 121.5 & 121.4 & $121.3(2)$ \\
\hline $\mathrm{C} 1$ & C6 & C5 & 118.4 & 117.7 & 117.7 & $117.6(2)$ \\
\hline $\mathrm{C} 1$ & C6 & C7 & 120.8 & 121.2 & 121.1 & 121.1(2) \\
\hline C5 & C6 & $\mathrm{C} 7$ & 120.8 & 121.1 & 121.1 & $121.2(2)$ \\
\hline C6 & $\mathrm{C} 7$ & C8 & 121.2 & 121.6 & 121.6 & $121.6(2)$ \\
\hline C6 & $\mathrm{C} 7$ & C12 & 121.4 & 121.7 & 121.6 & $121.8(3)$ \\
\hline $\mathrm{C} 8$ & $\mathrm{C} 7$ & C12 & 117.4 & 116.7 & 116.8 & $116.6(2)$ \\
\hline $\mathrm{C} 7$ & $\mathrm{C} 8$ & C9 & 121.3 & 122.1 & 122.0 & $121.9(2)$ \\
\hline C8 & C9 & C10 & 121.2 & 121.1 & 121.0 & $121.3(3)$ \\
\hline N2 & $\mathrm{C} 10$ & C9 & 119.2 & 121.5 & 121.5 & $121.5(3)$ \\
\hline N2 & C10 & C11 & 123.2 & 121.5 & 121.4 & $121.6(2)$ \\
\hline C9 & $\mathrm{C} 10$ & C11 & 117.6 & 117.0 & 117.1 & $116.9(2)$ \\
\hline $\mathrm{C} 10$ & C11 & C12 & 120.9 & 121.1 & 121.0 & $121.4(2)$ \\
\hline C7 & C12 & C11 & 121.6 & 122.1 & 122.0 & 121.8(3) \\
\hline N1 & C13 & C3 & 180.0 & 180.0 & 180.0 & $180.0(1)$ \\
\hline
\end{tabular}

and acceptor groups through $\pi$-electron movement. This $\pi$-electron cloud makes the molecule highly polarized and the intermolecular charge transfer interaction is highly responsible for the NLO properties of the title compound. Based on optimized geometries, the vibrational frequencies have been performed by the same methods and basis set. The vibrational bands assignments have been made by using Gauss-View molecular visualization program [16]. Theoretical results of the title compound are shown in Table 3. Nitrogen compounds featuring triple or cumulated double bonds, such as cyanides or nitriles $(-\mathrm{C} \equiv \mathrm{N})$ and cyanates $-\mathrm{O}-(\mathrm{C} \equiv \mathrm{N})$, all provide a unique spectrum, typically with a single, normally intense absorption at $2280-2200 \mathrm{~cm}^{-1}$ (for cyano compounds) and $2285-1990 \mathrm{~cm}^{-1}$ (for cyanates, isocyanates and thiocyanates) [17] [18]. The calculated value for the stretching mode $v \mathrm{C} \equiv \mathrm{N}$ with DFT-B3LYP is $2342 \mathrm{~cm}^{-1}$, Medium to weak absorption bands for the unconjugated $\mathrm{C}-\mathrm{N}$ linkage in primary, secondary and tertiary aliphatic amines appear in the region of $1250-1020 \mathrm{~cm}^{-1}$ [19]. The vibrations responsible for these bands involve C-N stretching couples with the stretching of adjacent bonds in the molecules. The position of absorption in this region depends on the class of amine and the pattern of substitution on the $\alpha$ carbon. Aromatic amines display strong C-N stretching absorption in $1342-1266 \mathrm{~cm}^{-1}$ region [19] [20]. The absorption appears at higher frequencies than the corresponding absorption of aliphatic amines because the force constant of the $\mathrm{C}-\mathrm{N}$ bond is increased by resonance with the ring. Louran et al. [21] reported a value at $1220 \mathrm{~cm}^{-1}$ for $v \mathrm{CN}$ for polyaniline. For the title compound the $v \mathrm{CN}$ mode is observed at $1203 \mathrm{~cm}^{-1}$ theoretically. For benzenes $v$ CH stretching mode are seen in the range $3230-3188 \mathrm{~cm}^{-1}, v$ CC stretching mode are seen in the range $1676-1447 \mathrm{~cm}^{-1}$ and $\delta \mathrm{CH}$ vibrations are seen in the range $1230-1280 \mathrm{~cm}^{-1}$ and 1170 $1000 \mathrm{~cm}^{-1}$ [21].We have observed theoretical values at 1480 to 1394 and 1312 to $1145 \mathrm{~cm}^{-1}$. The out-of-plane $\mathrm{CH}$ deformation bands $\omega \mathrm{CH}$ are expected in the range $740-990 \mathrm{~cm}^{-1}$ [21]. As seen from Table 3, the DFT-B3LYP calculation give wave numbers at $863,829 \mathrm{~cm}^{-1}$. The theoretical calculation Bands corresponding to $\mathrm{CH}_{3}$ asymmetric and symmetric bending vibrations are observed at $3150 \mathrm{~cm}^{-1}$ to $2995 \mathrm{~cm}^{-1}$ respectively. 
Table 3. Calculated vibrational spectra of the title compound $\left(\mathrm{C}_{15} \mathrm{H}_{14} \mathrm{~N}_{2}\right)$.

\begin{tabular}{|c|c|c|c|c|c|c|c|}
\hline & H F & B3LYP & В3PW91 & & H F & B3LYP & B3PW91 \\
\hline${ }_{v} \mathrm{CH}$ str & 3388 & 3230 & 3237 & $\beta \mathrm{CH}_{3}$ & 1165 & 1085 & 1086 \\
\hline$v \mathrm{CH}$ str & 3382 & 3229 & 3236 & $\delta \mathrm{CCC}, \beta \mathrm{CH}$ & 1131 & 1056 & 1060 \\
\hline$v \mathrm{CH}$ str & 3380 & 3216 & 3227 & $\delta \mathrm{CCC}, \beta \mathrm{CH}$ & 1115 & 1034 & 1033 \\
\hline$v \mathrm{CH}$ str & 3374 & 3215 & 3225 & $\tau \mathrm{CH}$ & 1110 & 1009 & 1007 \\
\hline$v$ CH str & 3364 & 3200 & 3209 & $\tau \mathrm{CH}$ & 1101 & 979 & 982 \\
\hline$v \mathrm{CH}$ str & 3363 & 3199 & 3209 & $\tau \mathrm{CH}$ & 1099 & 978 & 978 \\
\hline$v \mathrm{CH}$ str & 3351 & 3188 & 3197 & $\delta$ CCC, $\delta$ CCH & 1093 & 969 & 978 \\
\hline$v \mathrm{CH}$ str & 3350 & 3188 & 3197 & $\tau \mathrm{CH}$ & 1083 & 956 & 956 \\
\hline$v$ as $\mathrm{CH}_{3}$ str & 3302 & 3150 & 3164 & $\delta \mathrm{CCC}, \beta \mathrm{CNH}, \delta \mathrm{CNH}$ & 1040 & 956 & 954 \\
\hline$v$ as $\mathrm{CH}_{3}$ str & 3280 & 3138 & 3154 & $\omega \mathrm{CH}$ & 972 & 863 & 861 \\
\hline vs $\mathrm{CH}_{3} \mathrm{str}$ & 3242 & 3066 & 3074 & $\omega \mathrm{CH}$ & 955 & 854 & 853 \\
\hline$v \mathrm{~s} \mathrm{CH}_{3}$ str & 3234 & 3063 & 3070 & $\omega \mathrm{CH}$ & 941 & 829 & 826 \\
\hline$v \mathrm{~s} \mathrm{CH}_{3} \mathrm{str}$ & 3135 & 3003 & 3014 & $\tau \mathrm{CH}$ & 939 & 819 & 819 \\
\hline$v \mathrm{~s} \mathrm{CH}_{3} \mathrm{str}$ & 3124 & 2995 & 3006 & $\delta \mathrm{CCC}, v$ C3C13 str & 868 & 814 & 814 \\
\hline${ }_{v} \mathrm{C} \equiv \mathrm{N}$ str & 2601 & 2342 & 2351 & $\beta \mathrm{CH}$ & 833 & 764 & 767 \\
\hline$v \mathrm{C}-\mathrm{C}$ str,$v$ C6-C7 str & 1817 & 1676 & 1688 & $\delta$ CCC & 815 & 752 & 752 \\
\hline$v \mathrm{C}-\mathrm{C}$ str, $v$ C6-C7 str & 1813 & 1655 & 1667 & $\omega \mathrm{CH}, \beta \mathrm{CH}$ & 807 & 729 & 729 \\
\hline$v \mathrm{C}-\mathrm{C}$ str, $\delta \mathrm{C} 1 \mathrm{C} 6 \mathrm{C} 7, \delta \mathrm{C} 5 \mathrm{C} 6 \mathrm{C} 7$ & 1765 & 1610 & 1622 & $\delta \mathrm{CCC}, \delta$ C4C3C $13, \delta$ C2C3C 13 & 714 & 663 & 660 \\
\hline$v$ C-C str & 1739 & 1587 & 1598 & $\delta$ CCC & 700 & 651 & 648 \\
\hline$v \mathrm{C} 3 \mathrm{C} 13 \mathrm{str}, v \mathrm{C} 6-\mathrm{C} 7 \mathrm{str}, \delta \mathrm{CH}_{3}$ & 1702 & 1577 & 1584 & $v$ C6-C7 str, $\delta$ CCN, $\delta$ CNC & 661 & 631 & 634 \\
\hline$\delta \mathrm{CH}_{3}, v \mathrm{C} 10-\mathrm{N} 2 \mathrm{str}$ & 1672 & 1546 & 1546 & $\omega \mathrm{CH}$ & 644 & 583 & 581 \\
\hline$\delta \mathrm{CH}_{3}$ & 1653 & 1542 & 1538 & $\beta \mathrm{CH}$ & 631 & 565 & 565 \\
\hline$\delta \mathrm{CH}_{3}$ & 1636 & 1529 & 1524 & $\delta \mathrm{CCC}, \beta \mathrm{CH}, \delta \mathrm{CC} \equiv \mathrm{N}$ & 615 & 547 & 544 \\
\hline$\delta \mathrm{CH}_{3}$ & 1633 & 1502 & 1495 & $\delta \mathrm{CCC}, \delta \mathrm{CCN}, \beta \mathrm{CH}_{3}$ & 551 & 520 & 519 \\
\hline$\delta \mathrm{CH}_{3}$ & 1619 & 1499 & 1492 & $\delta$ CCC, $\delta$ CNC, $\beta \mathrm{CH}_{3}$ & 542 & 505 & 505 \\
\hline$\omega \mathrm{CH}_{3}$ & 1615 & 1494 & 1487 & $\beta \mathrm{CH}, \beta \mathrm{CNC}$ & 489 & 474 & 474 \\
\hline$\delta \mathrm{C}-\mathrm{H}, \omega \mathrm{CH}_{3}$ & 1587 & 1480 & 1482 & $\beta \mathrm{CH}, \delta \mathrm{C} 5 \mathrm{C} 6 \mathrm{C} 7$ & 476 & 431 & 430 \\
\hline$\delta \mathrm{C}-\mathrm{H}, \omega \mathrm{CH}_{3}$ & 1575 & 1458 & 1456 & $\tau \mathrm{CH}$ & 464 & 421 & 419 \\
\hline$\delta \mathrm{C}-\mathrm{H}, v \mathrm{C}-\mathrm{C}$ str, $\omega \mathrm{CH}_{3}$ & 1547 & 1447 & 1446 & $\tau \mathrm{CH}$ & 454 & 418 & 416 \\
\hline$\delta \mathrm{C}-\mathrm{H}, \delta \mathrm{CH}_{3}, v \mathrm{C} 10-\mathrm{N} 2 \mathrm{str}$ & 1487 & 1394 & 1406 & $\beta \mathrm{CH}_{3}, \delta \mathrm{CNC}$ & 424 & 415 & 412 \\
\hline$\beta \mathrm{CH}$ & 1460 & 1373 & 1388 & $\beta \mathrm{CH}_{3}, \delta \mathrm{CNC}$ & 424 & 415 & 412 \\
\hline$\beta \mathrm{CH}$ & 1445 & 1354 & 1362 & $\beta \mathrm{CH}, \beta \mathrm{CH}_{3}$ & 367 & 342 & 340 \\
\hline$v \mathrm{C} 6-\mathrm{C} 7 \mathrm{str}, \beta \mathrm{CH}$ & 1409 & 1336 & 1336 & $\beta \mathrm{CH}, \tau \mathrm{CH}_{3}$ & 320 & 264 & 259 \\
\hline$\delta \mathrm{CNH}, \beta \mathrm{CH}_{3}$ & 1364 & 1324 & 1331 & $\beta \mathrm{CH}, \tau \mathrm{CH}_{3}$ & 311 & 252 & 246 \\
\hline$\delta \mathrm{C}-\mathrm{H}$ & 1316 & 1312 & 1318 & $\beta \mathrm{CH}, \beta \mathrm{CH}_{3}$ & 256 & 227 & 226 \\
\hline$\delta \mathrm{C}-\mathrm{H}$ & 1309 & 1279 & 1295 & $\delta \mathrm{CNC}$ & 236 & 198 & 201 \\
\hline$\delta \mathrm{C}-\mathrm{H}+v \mathrm{C} 3-\mathrm{C} 13 \mathrm{str}$ & 1293 & 1242 & 1243 & $\beta \mathrm{CH}, \beta \mathrm{CH}_{3}$ & 208 & 178 & 176 \\
\hline$\delta \mathrm{C}-\mathrm{H}, \delta \mathrm{CNH}, \beta \mathrm{CH}_{3}$ & 1289 & 1229 & 1226 & $\beta \mathrm{CH}, \beta \mathrm{CH}_{3}$ & 183 & 155 & 155 \\
\hline$\delta \mathrm{C}-\mathrm{H}, \tau \mathrm{CH}_{3}, \delta \mathrm{CNH}$ & 1285 & 1208 & 1207 & $\beta \mathrm{CH}, \beta \mathrm{CH}_{3}$ & 162 & 116 & 112 \\
\hline$\delta \mathrm{C}-\mathrm{H}, v \mathrm{C}-\mathrm{N}$ str, $\tau \mathrm{CH}_{3}$ & 1275 & 1203 & 1200 & $\omega \mathrm{CH}_{3}$ & 119 & 87 & 86 \\
\hline$\delta \mathrm{C}-\mathrm{H}, \tau \mathrm{CH}_{3}$ & 1254 & 1167 & 1165 & $\omega \mathrm{CH}_{3}$ & 79 & 80 & 67 \\
\hline$\delta \mathrm{C}-\mathrm{H}, \tau \mathrm{CH}_{3}$ & 1217 & 1147 & 1145 & $\beta \mathrm{CH}, \omega \mathrm{CH}_{3}$ & 65 & 61 & 55 \\
\hline$\delta \mathrm{C}-\mathrm{H}, \tau \mathrm{CH}_{3}$ & 1213 & 1146 & 1145 & $\omega \mathrm{CH}_{3}$ & 44 & 55 & 52 \\
\hline$\delta \mathrm{C}-\mathrm{H}$ & 1201 & 1145 & 1138 & $\omega \mathrm{CH}_{3}$ & 42 & 37 & 33 \\
\hline
\end{tabular}

$v$ stretching modes (vs symmetric, $v$ as antisymmetric). $\delta$ in plane valence angle bending. $\tau, \omega, \beta$ : torsion out of plan, wagging and rocking deformations respectively. 
Table 4. (a) The electric dipole moment $\mu$ (D); (b) The average polarizability $\alpha_{\text {tot }}\left(\times 10^{-24}\right.$ esu); (c) The first hyperpolarizability $\beta_{\text {tot }}\left(\times 10^{-31} \mathrm{esu}\right)$.

(a)

\begin{tabular}{ccccc}
\hline & $\mu_{x}$ & $\mu_{y}$ & $\mu_{z}$ & $\mu_{\text {ТОт }}$ \\
\hline HF & 6.58 & -0.32 & 0.38 & $\mathbf{6 . 6 0}$ \\
B3LYP & -8.50 & 0.03 & 0.16 & $\mathbf{8 . 5 0}$ \\
B3PW91 & -8.66 & 0.03 & 0.12 & $\mathbf{8 . 6 6}$ \\
\hline
\end{tabular}

(b)

\begin{tabular}{cccccccc} 
& $\alpha_{x x}$ & $\alpha_{x y}$ & $\alpha_{y y}$ & $\alpha_{x z}$ & $\alpha_{y z}$ & $\alpha_{z z}$ & $\alpha_{\text {ТОт }}$ \\
\hline HF & 19.03 & -2.78 & 13.52 & 0.67 & 0.16 & 40.61 & $\mathbf{2 4 . 3 9}$ \\
B3LYP & 21.37 & -3.16 & 12.35 & 0.36 & 0.28 & 52.88 & $\mathbf{2 8 . 8 7}$ \\
B3PW91 & 21.26 & -3.17 & 12.48 & 0.31 & 0.16 & 52.90 & $\mathbf{2 8 . 8 8}$ \\
\hline
\end{tabular}

(c)

\begin{tabular}{cccccccccccc}
\hline & $\beta_{x x x}$ & $\beta_{x x y}$ & $\beta_{x y y}$ & $\beta_{y y y}$ & $\beta_{x x z}$ & $\beta_{x y z}$ & $\beta_{y z z}$ & $\beta_{x z z}$ & $\beta_{y z z}$ & $\beta_{\text {zzz }}$ & $\beta_{\text {тот }}$ \\
\hline HF & -4.49 & -0.90 & -0.37 & 1.00 & -0.09 & 1.54 & -5.50 & 3.49 & -0.48 & 105.35 & $\mathbf{9 9 . 7 7}$ \\
B3LYP & -1.57 & -0.24 & -0.62 & -1.72 & -13.08 & 5.80 & -8.71 & 4.16 & 1.09 & 511.67 & $\mathbf{4 8 9 . 8 8}$ \\
B3PW91 & -1.25 & -0.24 & -0.50 & -1.12 & -13.10 & 5.99 & -9.01 & 3.97 & 0.43 & 521.97 & $\mathbf{4 9 9 . 8 7}$ \\
\hline
\end{tabular}

\subsection{Hyperpolarizability Calculation}

As mentioned above, this study is extended to the determination of the electric dipole moment $\mu$, the isotropic polarizability $\alpha$ and the first hyperpolarizability $\beta$ of the title compound. Since the values of the polarizability $\alpha$ and the first hyperpolarizability $\beta$ of Gaussian 03 output are reported in atomic units (a.u.), the calculated values have been converted into electrostatic units (esu) $\left(\alpha: 1\right.$ a.u. $=0.1482 \times 10^{-24}$ esu; $\beta: 1$ a.u. $=8.6393 \times 10^{-33}$ esu). Table 4 listed the HF/6-31G(d, p), B3LYP/6-31G(d, P) ,B3LYP/6-31G/(d, p) results of the electronic dipole moment $\mu$, polarizability $\alpha$ and the first hyperpolarizability $\beta$ for 4,4' dimethylaminocyanobiphenyl. The highest value of dipole moment is calculated by B3PW91 is equal to $8.66 \mathrm{D}$ (Debye). The highest value of dipole moment is observed for component $\mu_{z}$. In this direction, this value is equal to $0.12 \mathrm{D}$. For direction $x$ and $y$, these values are equal to $-8.66 \mathrm{D}$ and $0.03 \mathrm{D}$ respectively. The dipole moment by HF and B3LYP values of the title compound are $6.60 \mathrm{D}, 8.50 \mathrm{D}$ respectively. The calculated polarizability $\alpha$ by HF, B3LYP and B3PW91 are equal to $24.39 \times 10^{-24}$ esu, $28.87 \times 10^{-24}$ esu, and $28.88 \times 10^{-24}$ respectively. As we can see in Table 4, the calculated polarizability $\alpha_{i j}$ have non zero values and was dominated by the diagonal components. The first hyperpolarizability values $\beta_{\text {tot }}$ of the title compound are equal to $99.77 \times 10^{-31}$ esu, $489.88 \times 10^{-31}$ esu and $499.87 \times$ $10^{-31}$ esu calculated by HF, B3LYP and B3PW91 respectively. The hyperpolarizability $\beta$ dominated by the longitudinal component of $\beta_{z z z}$. Domination of particular components indicates on a substantial delocalization of charges in these directions. Consequently, we can finally infer from the above discussion of the contents of Table 4 that the introduction of electron correlation in the method applied for the analysis of the hyperpolarizability, such as the DFT method, will probably predict more reasonable values as opposed to those converged upon use of the HF method, which yields very poor results.

\section{Conclusion}

In this work we have calculated the geometric parameters, the vibrational frequencies and the non linear optical properties of 4,4' dimethylaminocyanobiphenyl by using HF and DFT (B3LYP and B3PW91) methods. The optimized geometric bond lengths and bond angles obtained by using HF and DFT (B3LYP and B3PW91) show a good agreement with the experimental data. The comparison between the calculated vibrational frequencies by using HF and DFT methods indicates that B3PW91 is superior to the scaled HF and B3LYP approach for molecular vibrational problems. Nonlinear optical NLO behavior of the examined compound is investigated by the determination of the electric dipole moment, the polarizability and the hyperpolarizability by using the HF and DFT methods. 


\section{References}

[1] Brédas, J.L. (1994) Molecular Geometry and Nonlinear Optics. Science, 263, 487-488. http://dx.doi.org/10.1126/science.263.5146.487

[2] Jensen, L., Sylvester-Hvid, K.O. and Mikkelsen, K.V. (2003) Adipole Interaction Model for the Molecular Second Hyperpolarizability. Journal of Physical Chemistry A, 107, 2270-2276. http://dx.doi.org/10.1021/jp026208j

[3] Prasad, P.N. and Williams, D.J. (1991) Introduction to Nonlinear Optical Effects in Molecules and Polymers. Wiley, New York.

[4] Yanagi, K., Kobayashi, T. and Hashimoto, H. (2003) Origin of Transition Dipole-Moment Polarizability and Hyperpolarizability in Hydrazones. Physical Review B, 67, 115-122. http://dx.doi.org/10.1103/PhysRevB.67.115122

[5] Breitung, E.M., Shu, C.F. and McMahon, R.J. (2000) Thiazole and Thiophene Analogues of Donor-Acceptor Stilbenes: Molecular Hyperpolarizabilities and Structure-Property Relationships. Journal of the American Chemical Society, 122, 1154-1160. http://dx.doi.org/10.1021/ja9930364

[6] Hua, J.L., Li, J. and Luo, J.D. (2003) Recent Progress of Organic Second-Order Nonlinear Optical. Chinese Journal of Organic Chemistry, 23, 44.

[7] Kohn, W. and Sham, L.J. (1965) Self-Consistent Equations Including Exchange and Correlation Effects. Physical Review A, 140, 1133. http://dx.doi.org/10.1103/PhysRev.140.A1133

[8] Becke, A.D. (1988) Density-Functional Exchange-Energy Approximation with Correct Asymptotic Behavior. Physical Review A, 38, 3098. http://dx.doi.org/10.1103/PhysRevA.38.3098

[9] Lee, C., Yang, W. and Parr, R.G. (1988) Development of the Colle-Salvetti Correlation-Energy Formula into a Functional of the Electron Density, Physical Review B, 37, 785. http://dx.doi.org/10.1103/PhysRevB.37.785

[10] Flurry Jr., R.L. (1968) Molecular Orbital Theories of Bonding in Organic Molecules. Marcel Dekker Inc., New York.

[11] Perdew, J.P. and Wang, Y. (1992) Accurate and Simple Analytic Representation of the Electron-Gas Correlation Energy. Physical Review B, 45, 13244. http://dx.doi.org/10.1103/PhysRevB.45.13244

[12] Frisch, M.J., Trucks, G.W., Schlegel, H.B., Scuseria, G E., Robb, M.A., Cheeseman, J.R., Montgomery Jr., J.A., Vreven, T., Kudin, K.N., Burant, J.C., Millam, J.M., Iyengar, S.S., Tomasi, J., Barone, V., Mennucci, B., Cossi, M., Scalmani, G., Rega, N., Petersson, G.A., Nakatsuji, H., Hada, M., Ehara, M., Toyota, K., Fukuda, R., Hasegawa, J., Ishida, M., Nakajima, T., Honda, Y., Kitao, O., Nakai, H., Klene, M., Li, X., Knox, J.E., Hratchian, H.P., Cross, J.B., Adamo, C., Jaramillo, J., Gomperts, R., Stratmann, R.E., Yazyev, O., Austin, A.J., Cammi, R., Pomelli, C., Ochterski, J.W., Ayala, P.Y., Morokuma, K., Voth, G.A., Salvador, P., Dannenberg, J.J., Zakrzewski, V.G., Dapprich, S., Daniels, A.D., Strain, M.C., Farkas, O., Malick, D.K., Rabuck, A.D., Raghavachari, K., Foresman, J.B., Ortiz, J.V., Cui, Q., Baboul, A.G., Clifford, S., Cioslowski, J., Stefanov, B B., Liu, G., Liashenko, A., Piskorz, P., Komaromi, I., Martin, R.L., Fox, D.J., Keith, T., Al-Laham, M.A., Peng, C.Y., Nanayakkara, A., Challacombe, M., Gill, P.M.W., Johnson, B., Chen, W., Wong, M.W., Gonzalez, C. and Pople, J.A. (2004) Gaussian 03, Revision C.02 Program. Gaussian Inc., Wallingford.

[13] Kleinman, D.A. (1962) Nonlinear Dielectric Polarization in Optical Media. Physical Review, 126, 1977-1979. http://dx.doi.org/10.1103/PhysRev.126.1977

[14] Pipek, J. and Mezey, P.Z. (1989) A Fast Intrinsic Localization Procedure Applicable for ab Initio and Semiempirical Linear Combination of Atomic Orbital Wave Functions. Journal of Chemical Physics, 90, 4916-4926. http://dx.doi.org/10.1063/1.456588

[15] Zyss, J., Ledoux, I., Bertault, M. and E. (1991) Energy Dimethylaminocyanobiphenyl (DMACB): A New Optimized Molecular Crystal for Quadratic Nonlinear Optics in the Visible. Chemical Physics, 150, 125-135. http://dx.doi.org/10.1016/0301-0104(91)90062-X

[16] Frisch, A., Nielsen, A.B. and Holder, A.J. (2001) Gauss View Molecular Visualization Program. User Manual, Gaussian Inc., Pittsburg.

[17] Roeges, N.P.G. (1994) A Guide to the Complete Interpretation of Infrared Spectra of Organic Structures. Wiley, New York.

[18] Coates, J. (2000) Interpretation of Infrared Spectra, a Pratical Approach. John Wiley and Sons Ltd., Chichester.

[19] Silverstein, R.M. and Webster, F.X. (2003) Spectrometric Identification of Organic Compounds. 6th Edition, Wiley, New York.

[20] Colthup, N.B., Daly, L.H. and Wiberly, S.E. (1975) Introduction to Infrared and Raman Spectroscopy. Academic Press, New York.

[21] Louran, G., Lapkowski, M., Quillard, S., Pron, A., Buisson, J.B. and Lefrant, S. (1996) Vibrational Properties of Polyaniline Isotope Effects. Journal of Physical Chemistry, 100, 6998-7006. http://dx.doi.org/10.1021/jp953387e 